\title{
Los espectadores y el código del silencio
}

\author{
Julio César Carozzo C. \\ Presidente del Observatorio sobre la Violencia y Convivencia en la Escuela, Perú. Psicólogo. Ha sido Decano Nacional del \\ Colegio de Psicólogos del Perú. Correo electrónico: jccarozzo@observatorioperu.com
}

Recibido: Febrero 2014 • Aceptado: Mayo 2014

\section{RESUMEN}

El artículo se interesa en examinar las causas de la existencia de los llamados espectadores en el bullying (o acoso escolar entre iguales) y, en particular, hurgar en el porqué existen grupos de estudiantes que muestran una preocupante indiferencia cuando presencian el maltrato y abuso que se comete contra sus compañeros, algunos de los cuales, incluso, actúan aprobando y alentando al victimario sin importarles el sufrimiento de la víctima. También tenemos la intención de proponer las recomendaciones que sean necesarias para desmontar el llamado código del silencio que impera en las situaciones de bullying y acoso escolar.

Palabras clave: espectador, código del silencio, desensibilización.

\section{ABSTRACT}

The article focuses on examining the causes of the existence of the so-calledspectators in the bullying scene and in particular trying to dig inside the reason why these groups exist among students who show a disturbingindifference when they witness abuse committed against their peers, someof which even act approving and encouraging the perpetrator no matter the suffering of the victim. We also intend to propose recommendations that are necessary to dismantle the so-called code of silence that prevails in situations of bullying.

Keywords: spectator, code of silence, desensitization.

\section{Introducción}

Como bien se sabe, el fenómeno del bullying, además de los protagonistas directos, que son el agresor y la víctima, cuenta con un tercer protagonista al que se denomina espectadores, conformando de este modo la conocida triada del bullying. Difícilmente se podía imaginar o admitir que quienes se limitan a ser aparentemente meros espectadores de los incidentes de violencia en la escuela podrían ser considerados como parte del problema de violencia y, más difícil aún, reconocer que su intervención como espectadores es de especial valor en la perpetuación del bullying, así como también puede llegar a ser un factor de gran valor en la formulación de las políticas contra el bullying en la escuela.

Los espectadores tienen entre sus miembros individuos que asumen roles distintos, y este rasgo tampoco es irrelevante en la dinámica del bullying, por cuya razón no debe ser omitido en ninguna política de prevención e intervención que se implemente en los centros educativos. Es cierto que a los docentes y a los padres de familia se les ha atribuido una cuota de responsabilidad en el bullying, dada su inercia frente a los hechos de violencia que se suceden en la escuela, empero no por eso deben ser considerados como parte de 
los espectadores y cómplices pasivos, porque su presencia en el bullying no existe.

\section{¿Por qué el código del silencio?}

Para los niños y jóvenes, la sana complicidad es uno de los más importantes lazos de adhesión y cohesión entre ellos para todos sus avatares sociales y lúdicos, y en no pocos casos también para encubrir conductas que se asocian de alguna forma a transgresiones sociales en la familia y escuela. Los niños, en el hogar y en la escuela, están sometidos a un conjunto de reglas de conducta y de disciplina cuya rigidez restringe sus espacios y los intereses que requieren en sus relaciones interpersonales, en especial con sus coetáneos. Los adultos, incapaces de entender a los niños y convencidos de que la mejor crianza y educación consiste en imponer reglas de conducta a los menores, provocan en ellos grandes malestares y frustraciones que desean expresar, y expresan, de muchas formas, aunque los adultos, siempre miopes, solo reconocen las que atentan contra sus órdenes y mandatos.

En la escuela los niños y jóvenes tendrán oportunidad de experimentar la misma opresión contra las libertades que necesitan ejercitar y en estos casos las alianzas cómplices con otros compañeros empiezan a tener lugar y encienden las iras de los adultos (docentes y padres de familia) por su falta de sometimiento y obediencia. ¿Qué es lo que podemos ir deduciendo de estos casos? Que la complicidad tiene lugar en los niños, porque la sociedad adulta conspira contra los espacios de realización y satisfacción que buscan y necesitan. De modo que podemos inferir que la promoción de la convivencia en la escuela para la toma de decisiones sería un paso enorme en la educación de la solidaridad, la equidad y el respeto de los derechos, con lo que se desalentaría la existencia de conductas transgresoras y de complicidad que afecten el clima de la institución educativa.

Empero estas expresiones de complicidad en los niños no se muestra tan acusada como se puede encontrar a partir de la pubertad, cuando la necesidad de formar parte de grupos se hace más imperativa, porque sus demandas sociales y personales son mayores y muchas de ellas conciernen a su intimidad. Son estos momentos, los de la emergencia de nuevas necesidades, los que la sociedad adulta reprimirá sin mayor contemplación y se empezarán a polarizar los desencuentros y la tentación de someter y controlar las conductas de los jóvenes por parte de los adultos, así como también es posible que se exacerben los códigos internos de los jóvenes como medidas de seguridad y protección ante la arremetida de los adultos.

La complicidad y la resistencia entre los escolares resulta una suerte de conquista sobre el autoritarismo que provocativamente espetan casi siempre los adultos. Nunca como en esos casos los niños y los jóvenes se sienten tan unidos, gozosos y desafiantes al orden que los limita en sus sueños y en la incontrolable ambición por conocer su entorno y acomodarlo como su percepción lo cataloga, y disfrutarlo tan solo por el mero hecho de que ellos así pueden apropiarse e interiorizar la realidad investida de su pujante subjetividad que no admite las rigideces que los adultos tienen la manida costumbre de imponer.

De este modo los niños, niñas y jóvenes tienen la oportunidad de representarse la realidad con base en sus necesidades e intereses, que no siempre pueden llegar a ser los que el mundo adulto les reclama, a buena o mala hora. Los adultos creemos ser el orden, la disciplina, el ideal por imitar o seguir, y por eso somos rígidos y levantamos muchas barreras que nos alejan de los niños y jóvenes. Solo les permitimos una puerta de acceso para que merezcan nuestro reconocimiento: que se comporten como adultos, dejando de ser niños y jóvenes. Esa es la concesión que les ofrecemos a ellos.

La etapa de la sumisión y pasividad que buscamos en los menores no ha existido nunca, porque desde el momento en que el niño empieza su fase de investigación-experimentación (como la llamaba Pavlov) al iniciar su deambulación bípeda, la intención de valerse de su autonomía para desbordar los espacios a que está limitado por los adultos son crecientemente mayores y es allí en 
donde el universo adulto trata con más intensidad de contener la exuberancia práxica de los niños, con lo cual se corre el riesgo de apagar la sed de conocimientos que están íntimamente vinculados a la exploración-investigación. La praxis hace la gnosis, nos enseñaba con maestría Merani (1965).

\section{La cultura del silencio y la discapacidad social}

En verdad, la indolencia y la pasividad frente al abuso es un histórico modelo de vivir en paz, sin complicaciones. "No te metas en problemas o conflictos que no son tuyos", enseñan los padres a sus hijos, y su devastadora consecuencia aún no es apreciada en su real dimensión. Esta cultura premia la docilidad y el inmovilismo al tiempo que denosta y castiga la desobediencia y la insubordinación contra sus preceptos. Desde muy temprano los niños reciben cursos prácticos de sojuzgamiento y pasividad a las decisiones provenientes de sus mayores de la casa: la obediencia y la disciplina consistentes en aceptar todo lo que se les imponga y la pasividad de los receptores son las reglas de oro en la buena crianza. Se castiga y estigmatiza toda forma de cuestionar y desacatar los modelos de comportamiento ordenados sin importar la pertinencia de los reclamos: la violación de los derechos de los niños y la resignación a esta forma de violencia es un curso acelerado y transversal en los hogares como escenario sincrético de la sociedad.

Los que se muestran reacios a aceptar estas relaciones de poder-sumisión, sin importar su edad, son castigados y escarmentados severamente para erradicar de raíz una rebeldía inadmisible al orden supremo que los padres y docentes creen representar. Lo que queremos decir es que el propio sistema social y su cultura se encargan de enseñar a los niños, niñas y jóvenes la importancia de no reaccionar ante lo que pasa en nuestro entorno, por repulsivo que ello sea, y la mayor sutileza que emplean para conservar esa actitud es la de motejar de indignos soplones a quienes denuncien a los responsables de las faltas e infracciones. ¿Qué niño, niña o joven puede denunciar a sus padres de violencia familiar sin ser señalado como desleal y traidor a su familia? El germen de la mimetización a cualquier cuadro de violencia social ya está sembrado y en adelante la conducta de la indiferencia irá cobrando variadas modalidades.

La indiferencia es inmoral, porque no afecta la conciencia moral en la percepción de hechos que deberían afectarla. La indiferencia aletarga, inmoviliza, aliena y deshumaniza a la persona. La indiferencia y la pasividad son parte de un proceso de desensibilización aprendida que es preciso revocar en las escuelas, lugar privilegiado para enseñar a convivir democráticamente.

Un referente complementario a lo que estamos exponiendo es que nuestra cultura considera a los niños y jóvenes como discapacitados sociales incapaces de entender lo que es bueno para ellos y, sobre todo, carentes de habilidades y competencias para hacer algo que les provea bienestar y satisfacción a sus expectativas, y a partir de esta consideración se consagra una relación insufrible de poder-sumisión que, en la mayoría de los chicos, estimula los círculos de complicidad, sin pasar por alto que años más tarde el desinterés o temor de los padres de abordar la orientación de los hijos en materia de sexo y drogas, por ejemplo, lo que tampoco es atendido por los docentes en la escuela, configura otro empujón más para afirmarse en el grupo al cual están adscritos y en donde sí encuentran respuestas a sus crisis existenciales y reales, aunque la precariedad de la información que se maneja expone a los jóvenes a nuevas situaciones de riesgo.

La verticalidad que imponen los adultos a los menores y su impericia para cumplir su función educadora con los hijos y estudiantes están matizadas siempre de violencia, porque los adultos siguen confiando en la necesidad y utilidad del castigo para alcanzar los objetivos que se desean y de ese modo se proporciona a los menores otro aprendizaje: el que tiene más poder debe ejercerlo para lograr sus objetivos, cualquiera que ellos fueran. En el hogar y en la escuela, que son los espacios más inmediatos donde los niños se socializan, han aprendido que la violencia es una forma de conseguir lo que el más fuerte se propone $\mathrm{y}$, lo que han visto y aprendido en el hogar 
y en la escuela, empieza a ser imitado. Allí también han aprendido que deben colocarse al lado de quien ostenta mayor poder si no desean ser amenazados o agredidos, es decir, se convierten en espectadores de la violencia familiar y escolar.

\section{Los espectadores y el bullying}

Una ilustración pertinente sobre los espectadores. No todos ellos son iguales o, para mejor entenderlo, los roles que desempeñan los espectadores son distintos entre sí. Están los que se muestran abiertamente partidarios del agresor, y no son pocos; otro sector de ellos siente una íntima solidaridad con la víctima, la que raramente expresan en forma manifiesta, y los hay quienes son indiferentes a los acontecimientos. La inacción de todos ellos, sea cual sea su sentimiento, es lo que impera en el fenómeno del bullying y esa paralización de los espectadores actúa devastadoramente sobre la víctima, que se siente y se sabe completamente desprotegida.

La importancia que tienen los espectadores en el estudio de la dinámica del bullying ha merecido una atención especial por parte de los estudiosos y en ellos se destacan explicaciones comunes del porqué del silencio que domina su rol. Se considera que el temor de que sean elegidos como futuras víctimas es un poderoso motivo para su silencio; también la falta de habilidades sociales para intervenir en la relación de violencia que limita su accionar, e incluso la creencia de que los niños y jóvenes están tan habituados a los actos de violencia en los distintos ámbitos sociales que se mimetizan a su ocurrencia en la escuela y la perciben como normal y natural. Sin embargo, debemos decir que estas explicaciones nos parecen muy simplistas y no nos convencen plenamente, aunque algunas de ellas tengan bastante de cierto, aparentemente.

También es notorio que casi todas las explicaciones que se han proporcionado sobre el papel de los espectadores en el bullying giran únicamente en torno al hecho de la violencia en sí misma, soslayándose una mirada holística, más social, de la conducta de los espectadores y del fenómeno del bullying que, como señalamos líneas arriba, reconoce numerosos eslabones de la cultura de la sociedad, la familia y la escuela, como para dejar de evaluarlos como indiscutibles condicionantes comportamentales, los que al ignorarlos e invisibilizarlos por completo dejan de ser abordados y con ello se elimina un mejor conocimiento de este fenómeno así como de su influencia, haciendo estériles los cambios que se proponen desde la escuela. Este hecho nos lleva a comprender que las medidas preventivas y correctivas por aplicarse deben comprender, cuanto menos, el escenario escolar y el familiar.

J. M. Avilés (2012), al explicar el perfil de los protagonistas del bullying, destaca que los espectadores son pasivos ante los actos de violencia contra uno de sus compañeros, porque consideran que no es asunto suyo y no tienen por qué inmiscuirse (indiferentes), o porque temen ser elegidos como las próximas víctimas del matón por el hecho de oponerse a él (miedo a intervenir) y están aquellos que piensan que las víctimas se merecen lo que les ocurre por no saber defenderse (connivencia de los testigos).

En su libro, Isabel Fernández (2005) hace más énfasis sobre las consecuencias del bullying en sus protagonistas $y$, al referirse a los espectadores, afirma que en ellos destaca su actitud pasiva y complaciente ante la injusticia y un modelado equivocado de la valía personal. Además de manifestar una clara falta de solidaridad.

Sin embargo, la pasividad o indolencia que muestran los espectadores no se limita al temor frente al agresor y a la recurrente tolerancia de todos respecto del agresor en la escuela, sino que a ello se debe añadir la formación que nuestra cultura nos provee y tiene el sello de la no solidaridad con el otro.

El Informe del Defensor del Pueblo (1999) coincide con otras afirmaciones, al sostener que se ha demostrado que el miedo a ser incluido dentro del círculo de victimización y convertirse también en blanco de agresiones impide que el alumnado que siente que debería hacer algo lo haga.

Por su parte, Rosario Ortega (1998) nos dice que el espectador experimenta una disonancia moral de culpabilidad, porque le están pidiendo 
que aplauda, o al menos ignore, una crueldad de la que el espectador no es responsable como agente, pero sí como consentidor. El espectador del abuso entre compañeros puede también verse moralmente implicado, cuando participa de convenciones y falsas normas referidas a la necesidad de callar, es la ley del silencio.

En Díaz-Aguado (2005), encontramos una indirecta explicación del rol de los espectadores cuando, al hablar sobre el papel de los compañeros frente a la exclusión y el acoso, admite la especial importancia que viene cobrando el estudio del papel de los compañeros que no participan directamente en el acoso y destaca que la pasividad de los espectadores guarda relación con el perfil de la víctima, porque ellos se encuentran habitualmente aislados, no tienen amigos y son bastante impopulares.

Como se puede apreciar, de todas estas explicaciones que hemos recogido, los factores que incidirían esencialmente en la existencia de los espectadores son de carácter individual, es decir, o el temor ante lo que pueda hacer el agresor, la falta de habilidades sociales para intervenir y frenar las acciones de violencia, la antipatía hacia el compañero o el no tener vínculos de amistad con la víctima. Los factores de riesgo, entonces, para la existencia de los espectadores indolentes e indiferentes parecen ser estrictamente individuales y personales; $y$, por tanto, toda medida educativa o interventiva debe ser dirigida a la individualidad del agente. Lo que los individuos puedan haber recogido de su entorno social a través de su proceso de socialización, no tendría mayor relevancia, según parece, lo que configuraría una grave omisión.

En lo personal pienso que el llamado código del silencio (individual y social) es una característica muy propia de la conducta de los individuos en sus diversas etapas de vida, gracias a la cual las organizaciones y grupos sociales alcanzan a distinguirse entre sí con base en rigurosos códigos que los identifican y califican. Tendenciosamente se ha atribuido que los códigos de cohesión solo existen entre los grupos antisociales y delictivos para protegerse de infiltrados o agentes de la ley.
Pero no, los grupos, sea cual fuere su estructura y naturaleza, fundan su cohesión en el reconocimiento de códigos de solidaridad y seguridad para garantizar su identidad y durabilidad. Como se sabe, cuanto más cerradas son las organizaciones, mayores son las exigencias de observar y respetar meticulosamente los códigos institucionales.

Carozzo (2012) afirma que las conductas de indiferencia y silencio ante la violencia entre pares existen porque el sistema social no tolera ni premia la denuncia contra toda forma de relaciones sociales que emane de la entraña misma de su organización y, para asegurarse este tipo de respuestas, históricamente ha sentado una clara política de castigo cuando ellas se han promovido y producido al margen de su decisión última. Las excrecencias de la gestión social solo pueden ser subsanadas o sancionadas por las autoridades y las normas que ellas dispongan, mediante lo cual se infiere que las estrategias de prevención por procurarse son descendentes y anulan cualquier participación de las propias víctimas de la violencia.

En el particular caso del bullying no caben excepciones, pese a que aquí nos encontramos con un hecho histórico que importa puntualizar y que explicaría el porqué de la resistencia de las víctimas y de los espectadores a denunciar las acciones de acoso. Como ya se conoce, el bullying es un problema muy antiguo en la escuela y durante ese tiempo los estudiantes han sido "instruidos" tácitamente en la sumisión y la tolerancia a todo tipo de maltratos que ocurren dentro de la escuela. Lo que allí ocurre no debe trascender y en última instancia el único lugar en donde se deben resolver los entuertos de los alumnos es en la propia escuela. Los "trapos sucios se lavan en casa", reza una conseja popular, lo que también se impuso en el seno de las familias y se constituyó en el baluarte de la violencia familiar por mucho tiempo, de donde proviene otro aditamento para solidificar la postura de silencio e indiferencia de los niños y jóvenes: "no metas las narices en donde no te llaman", les dicen los padres a sus hijos, convencidos de que están protegiéndolos de riesgos innecesarios. 
Aunque no en una forma abierta, nuestra cultura social no alienta que la víctimas directas e indirectas del bullying expresen orgánicamente su rechazo a una práctica de violencia que las daña, porque le es más conveniente mantener la pasividad y la sumisión de los estudiantes, antes que la asunción de una postura cuestionadora de los estilos relacionales y de "convivencia" que ella propone. Pero sí se ha preocupado en crear una suerte de violencia simbólica en la que se refugian argucias que consagran la normalidad de la violencia; la normal tendencia a la culpabilización en la víctima, que se atribuye a sí misma el origen de su condición de víctima o también los denominados "perfiles" de víctima y agresor, que lavan la conciencia de los auténticos responsables del bullying en las escuelas.

Es así como el sistema y la cultura propician, además del acoso a las víctimas, su silencio, su pasividad, su indiferencia y su complicidad con el agresor. Aquí está en su máximo esplendor lo que se conoce como la conspiración o el código del silencio, lo que el sistema educativo pretende eliminar mediante medidas sancionadoras contra los cómplices pasivos.

Finalmente no debemos dejar de señalar que, al contrario de lo que pudiese parecer, los espectadores no salen indemnes de su rol de indiferencia o mero reforzador verbal del incidente de agresión. Claro está que lo primero que debemos mencionar es que, en estas repetidas experiencias por las que atraviesa el espectador, se desarrollará en él una cruda desensibilización que lo distancia cada vez más de la opción de intervenir en apoyo a su compañero agredido; acrecienta su insolidaridad y refuerza su posición egoísta y, lo que es grave, que estos estilos de conducta se hacen extensivos a otros ámbitos en donde debe participar socialmente. Los efectos psicológicos que experimentan los espectadores pueden ser muy parecidos a los que presentan los agresores y las víctimas.

Le Bon, citado por Klineberg (1965), decía que cuando el individuo se encuentra formando parte de un grupo, sus reacciones de violencia se ven facilitadas, porque cuenta con que el grupo le ofrece la sensación de impunidad. Muchos o algunos espectadores, habitualmente sosegados e inofensivos, cambian su comportamiento solo cuando se encuentran integrando un grupo, donde se expresan en forma frenética y virulenta durante el lapso en que actúan dentro de él. Pero, para que esto se produzca, hay que considerar los aprendizajes sociales con los que cuentan los individuos, es decir, que no es suficiente el grupo.

\section{¿Se puede acabar con la ley del silencio?}

El llamado código del silencio existe esencialmente allí donde dominan relaciones de podersumisión, sea cual sea el contexto relacional. Rara vez lo hallamos en las relaciones entre camaradas y amigos, que son de iguales y marcadas por significativas coincidencias que gestan la cohesión y fortaleza del grupo, en donde el espíritu dominante es justamente el grado de conocimiento e información que todos dominan sobre sus motivaciones, necesidades, intereses y dinámica, que es donde afinca su fortaleza e identidad.

$\mathrm{Si}$, como lo hemos venido sosteniendo, la aparición y la variación de situaciones de complicidad en los niños y adolescentes tiene mucho que ver con los estilos de vida social, familiar y escolar, la propuesta de intentar acabar con el silencio cómplice en ellos pasa necesariamente por la revocación de los modelos culturales que los promueven y alientan, y no a la inversa como se piensa y quiere, es decir, desautorizando moral y reglamentariamente la práctica del silencio en los espectadores del bullying sin tomar en cuenta la historia de su existencia y accionando sobre esos espacios sociales en donde se encuentra arraigada.

La ingenua complicidad que surge entre los niños como una forma de eludir rígidas exigencias de los adultos y que deviene en soporte significativo en la cohesión de sus relaciones interpersonales y vínculos lúdicos, provee tantos réditos y satisfacciones a los niños y niñas que su ejercicio se convierte en elemento importante dentro de su socialización. El origen de esta complicidad, como queda dicho, es consecuencia de la actitud vertical y excluyente que los adultos tienen con los niños -los discapacitados sociales-a quienes 
creen que deben trazarles su camino y ordenarles sus gustos y tareas que deben cumplir sin opción de protestar.

La agudización de los roles cómplices tiene lugar con el despertar de la pubertad y la adolescencia, porque las nuevas y urgentes necesidades que emergen en ellos encuentra que los adultos no quieren o se resisten a comprender atemorizados por los prejuicios sociales que los abruman, como son los casos de la psicosexualidad y el enamoramiento, por ejemplo, y los chicos y chicas cierran filas en torno a una más provocativa complicidad como forma de encontrar respuestas a sus dudas existenciales y reales. Nuevamente hallamos que la distancia que los adultos han establecido con los chicos se produce justamente en momentos en que requieren de urgente orientación para el manejo de sus emociones y sentimientos. Estos desencuentros, provocados básicamente por los adultos, son los aguijones para un mayor afianzamiento de los códigos y secretismos entre sí y la tendencia más desenfadada para la transgresión y la irreverencia.

En consecuencia, podemos afirmar que, si desde las más tempranas edades el niño es educado en gestión y resolución de conflictos y se le forja en el respeto de los derechos del otro en forma equitativa y solidaria, se le enseña el valor de la tolerancia y la empatía con las correspondientes competencias emocionales para las relaciones y los conflictos, es probable que la complicidad decaiga y la indiferencia hacia el otro se elimine, en tanto el buen trato y la convivencia democrática cobre un estatuto de institucionalización social fundamental para la mejor adecuación de los niños a su universo relacional.

Actitud semejante es la que tiene que observarse en las relaciones con los púberes y adolescentes si se quiere conseguir una mayor y mejor relación interpersonal basada en la confianza y el respeto afectuoso. Estas medidas se orientan para la superación de la complicidad en materia de relaciones de violencia, no para todo tipo de complicidad que se gastan los individuos.

Sin embargo, se conocen algunos factores que al ser empleados contribuyen a desalentar el llamado código del silencio (Mendoza, 2012). Ellos han sido apreciados en nuestro trabajo contando que no son las personas las que deben cambiar solamente, como es obvio, y por ello la visión en este campo sigue siendo ecológica:

La edad: Los niños tienen una mayor facilidad en contar lo que les pasa o lo que ven en la escuela. Sin embargo, es conveniente que los padres y los docentes alienten un diálogo con los niños sobre sus experiencias escolares y familiares.

Clima escolar democrático y equitativo: si estas condiciones tienen lugar, los estudiantes sentirán un clima de confianza y seguridad. El bienestar que les provee la escuela es un poderoso aliciente para desarrollar competencias emocionales y sociales de relación.

Monitoreo constante: las normas de convivencia que se acuerden deben ser recordadas y reforzadas estimulando conductas prosociales, dentro de un enfoque de competencias.

Trato justo y afectivo: les ayuda a los niños y jóvenes a sentirse reconocidos, valorados y respetados, lo que con seguridad representa una buena forma de enseñarles a ser empáticos.

En resumen, la escuela y la familia tienen una gran responsabilidad en la educación de los niños y adolescentes en procura de que el espectador devenga en un factor de seguridad en la escuela a través de su activa participación en programas de habilidades y competencias para la vida que deben ser creados en las instituciones educativas, todo ello en un marco de respeto y equidad.

\section{Referencias bibliográficas}

Avilés M., José María (2012). Manual contra el bullying. Guía para el profesorado. Lima: Ediciones Libro Amigo.

Carozzo, Julio César (2012). Bullying en la escuela: interrogantes y reflexiones. En Benites, L., Carozzo, J., Horna, V., Palomino, L., Salgado, C., Uribe, C. y Zapata, L. (2012). Bullying y convivencia en la escuela. Aspectos conceptuales, aplicativos y de investigación. (p.p. 11-37). Lima: Dennis Morzan Delgado. 
Carozzo, Julio, Benites, Luis, Horma, Víctor y Zapata, Luis (2012). El bullying no es juego. Guía para todos. Lima: Dennis Morzan Delgado.

Díaz-Aguado, María José (2005). Por qué se produce la violencia escolar y cómo prevenirla. Revista Iberoamericana de Educación. Monográfico, núm. 37. Madrid. España.

Fernández, Isabel (2005). Escuela sin violencia. Resolución de conflictos. Lima: Alfaomega-Narcea.

Klineberg, Otto (1965). Psicología Social. México: Fondo de Cultura Económica.

Mendoza, Brenda (2012). Bullying. Los múltiples rostros del acoso escolar. Argentina: Brujas.

Merani, Alberto (1965). De la praxis a la razón: mano, cerebro y lenguaje. Barcelona: Grijalbo.
Merino, César, Carozzo, Julio, Benites, Luis (2012). Bullying in Perú. A code of silence? Handbook of School Violence and School Safety. Edited by Shane R. Jimerson, Amanda B. Nickerson, Mattew J. Mayer y Michael J. Furlong. New York.

OÑaTE Aaraceli y Piñuel, Inaki (2005). Informe Cisneros VII. Violencia y acoso escolar en alumnos de primaria, ESO y Bachiller. Instituto de Innovación Educativa y Desarrollo Directivo. Recuperado de <www.uned.es/dpto_pen/ delincuencia-juv/documento $>$.

Ortega, Rosario y colaboradores (1998). La convivencia escolar: qué es y como abordarla. España: Consejería de Educación y Ciencia. Junta de Andalucía. 